\title{
Pengaruh Keselamatan Kerja Terhadap Kinerja Karyawan Pada PT. PLN (Persero) Unit Induk Pembangunan II Medan
}

\section{Determinan of Safety Work on Employees Performance in PT. PLN (Persero) Unit Induk Pembangunan II Medan}

\section{Lukman Nasution2) \& Reza Nurul Ichsan 1),}

1) Program Studi Manajemen, Fakultas Ekonomi, Universitas Muslim Nusantara Al washliyah Medan, Indonesia

2) Program Studi Manajemen, Fakultas Ekonomi, Universitas Pembinaan Masyarakat Indonesia, Indonesia

Diterima :16 September 2020 ; Direview: 26 September 2020 ; Disetujui : 14 Oktober 2020

*Coresponding Email: rezaichsan31@gmail.com

\section{Abstrak}

Penelitian ini bertujuan untuk mengetahui besarnya pengaruh keselamatan kerja terhadap kinerja karyawan pada PT. PLN (Persero) Unit Induk Pembangunan II Medan. Penelitian ini dilaksanakan pada lingkup PT. PLN (Persero) Unit Induk Pembangunan II Medan. Sampel diambil adalah sebanyak 30 Responden dan metode analisis yang dipakai adalah analisis regresi linier sederhana dimana konstanta sebesar 6,541 yang artinya menunjukkan bahwa jika variabel konstanta maka tingkat variabel kinerja karyawan nilainya positif yaitu sebesar 0,771 yang artinya jika keselamatan kerja mengalami kenaikan sebesar 1 persen maka kinerja karyawan akan mengalami peningkatan sebesar 0,771, kedua variabel ini saling memiliki hubungan keterikatan yang positif terhadap kinerja karyawan serta memiliki nilai signifikannya adalah 0,000 < dari 0,005. Hasil analisis Uji t menghasilkan nilai tHitung adalah sebesar 7,366 lebih besar dari nilai tTabel sebesar 2,763, artinya variabel keselamatan kerja berpengaruh signifikan terhadap kinerja karyawan.

Kata Kunci: Keselamatan Kerja; Kinerja Karyawan.

\begin{abstract}
This study aims to determine the magnitude of the effect of occupational safety on employee performance on PT. PLN (Persero) Unit Induk Pembangunan II Medan, This study was conducted on the scope of PT. PLN (Persero) Unit Induk Pembangunan II Medan. Samples were taken as many as 30 Respondents and the analytical method used is simple linear regression analysis where the constant is 6,541 which means that if constant variable then the level of employee performance variable is positive value that is equal to 0,771 which means if work safety have increase by 1 percent hence employee performance will experience increase equal to 0,771, second These variables have a positive attachment relationship to employee performance and have significant value is $0.000<$ from 0.005. Result of t test analysis yield $t$ value is equal to 7,366 bigger than tTabel value equal to 2,763, meaning work safety variable have significant effect to employee performance.

Keywords: Safety, Employee Performance.

How to Cite: Nasution, L. \& Ichsan, R.N. (2020). Pengaruh Keselamatan Kerja Terhadap Kinerja Karyawan Pada PT. PLN (PERSERO) Unit Induk Pembangunan II Medan. Journal of Education, Humaniora and Social Sciences (JEHSS). 3(2): 452-458.
\end{abstract}




\section{PENDAHULUAN}

Keselamatan kerja merupakan bagian dari pemeliharaan sumber daya manusia. Keselamatan kerja perlu diperhatikan untuk meningkatkan hasil pekerjaan di dalam perusahaan masalah ini sangat berpengaruh terhadap sehat tidaknya karyawan untuk melaksanakan tugasanya. Keselamatan dan kesehatan kerja dapat diartikan sebagai ilmu pengetahuan yang diterapkan dalam usaha mencegah kemungkinan terjadinya kecelakaan akibat melaksanakan tugas di tempat kerja. Keselamatan kerja dalam suatu organisasi harus dilaksanakan secara bersama-sama baik oleh pimpinan maupun karyawan sehingga kemungkinan terjadinya kecelakaan dapat terhindarkan. Dalam implementasinya pemimpin dapat membantu petugas keselamatan di tempat kerja dengan mempersiapkan devisi dan tenaga yang terampil di bidang keselamatan kerja.

Kinerja karyawan merupakan hal yang bersifat individual, karena setiap karyawan mempunyai tingkat kemampuan yang berbeda-beda dalam mengerjakan tugasnya. Pihak manajemen dapat mengukur kinerja karyawan dari masing-masing karyawan. Kinerja tergantung pada kombinasi antara kemampuan, usaha, dan kesempatan yang diperoleh. Hal ini dapat dilihat dari kinerja karyawan dalam bekerja, untuk periode waktu tertentu untuk penekanannya pada hasil kerja yang diselesaikan karyawan dalam periode waktu tertentu. Faktor yang mempengruhi kinerja karyawan adalah dengan adanya keselamatan kerja dalam perusahaan dan dapat diterima oleh seluruh karyawan (Mora, Z., et al., 2020; Latief, et al., 2019; Latief, et al., 2019).

Setiap organisasi/perusahaan memiliki kewajiban untuk memastikan bahwa pekerja dan orang lain akan terlibat tetap berada dalam kondisi aman sepanjang waktu. Tempat kerja yang aman dan sehat diperlukan setiap orang agar dapat melaksanakan pekerjaannya secara efektif dan efisien. Sebaliknya, jika tempat kerja tidak terorganisir dan banyak terdapat bahaya, maka kerusakan tidak akan terhindarkan, sehingga mengakibatkan kurangnya kinerja dan hilangnya pendapatan bagi pekerja. Apabila perusahaan memperhatikan hal tersebut akan dapat meningkatkan kinerja karyawan sesuai dengan tujuan dan sasaran perusahaan (Latief, et al., 2018; Syardiansah, et al., 2020; Haryati, et al., 2019).

Pada PT. PLN (Persero) Unit Induk Pembangunan II Medan sebenarnya sudah sangat memperhatikan akan keselamatan kerja tersebut. Namun, karena para karyawan kadang sepele dengan pekerjaannya sehingga mengakibatkan kecelakaan ataupun mengganggu kesehatan. Berdasarkan masalah tersebut diatas maka penulis akan melakukan penelitian dengan judul: "Pengaruh Keselamatan Kerja Terhadap Kinerja Karyawan pada PT. PLN (Persero) Unit Induk Pembangunan II Medan".

\section{METODE PENELITIAN}

Pada penelitian ini data yang diperoleh dengan menggunakan metode yang telah direncanakan dan ditentukan sebelumnnya. Metode pengumpulan data adalah suatu cara yang sistematis dan objektif yang diperoleh melalui cara-cara pengumpulan data dengan tujuan memperoleh atau mengumpulkan data dengan tujuan memperoleh atau mengumpulkan keterangan-keterangan yang bersifat lisan ataupun tulisan.

Metode penelitian yang digunakan dalam penelitian ini terdiri dari dua cara, yaitu: (1) Penelitian Kepustakaan (Library Research) dan (2) Penelitian Lapangan (Field Research).

Sumber data yang dilakukan dalam penelitian ini adalah Data Kuantitatif. Data kuantitatif yaitu data yang diperoleh dalam bentuk angka - angka yang dapat dihitung, yang diperoleh dari wawancara dan kuesioner dari karyawan yang ada di PT. PLN (Persero) Unit Induk Pembangunan II Medan. Teknik analisis data dalam penelitian ini dengan menggunakan: Uji t (Parsial), Uji F (Serempak), dan Uji Koefisien Determinasi (R-Square/R2). Penghitungan uji analisis dalam penelitian ini dilakukan dengan menggunakan bantuan program Statistical Package for Social Science (SPSS). 
Lukman Nasution \& Reza Nurul Ichsan \&, Pengaruh Keselamatan Kerja Terhadap Kinerja Karyawan Pada

HASIL DAN PEMBAHASAN

Statistik Deskriptif Variabel Penelitian

Tabel 1.

Uji Validitas Variabel Keselamatan Kerja (X)

\begin{tabular}{ccc}
\hline Item & Corrected Item-Total Correlation & Keterangan \\
\hline 1 & 0,557 & Valid \\
\hline 2 & 0,686 & Valid \\
\hline 3 & 0,550 & Valid \\
\hline 4 & 0,627 & Valid \\
\hline 5 & 0,665 & Valid \\
\hline 6 & 0,593 & Valid \\
\hline \multicolumn{3}{c}{ Sumber: Hasil Olahan SPSS 21, (2017) }
\end{tabular}

Setelah di uji validitas variabel X1 (Keselamatan Kerja) Item pertanyaan sebanyak 6 semua dinyatakan valid karena nilai corrected item-total correlation $>0,3$.

Tabel 2

Uji Validitas Variabel Kinerja Karyawan (Y)

\begin{tabular}{ccc}
\hline \multirow{2}{*}{ Item } & Corrected Item-Total Correlation & Keterangan \\
\hline 1 & 0,663 & Valid \\
\hline 2 & 0,689 & Valid \\
\hline 3 & 0,656 & Valid \\
\hline 4 & 0,626 & Valid \\
\hline 5 & 0,402 & Valid \\
\hline 6 & 0,767 & Valid \\
\hline
\end{tabular}

Sumber: Hasil Olahan SPSS 21, (2017)

Sedangkan uji validitas variabel Y (Kinerja Karyawan) item pertanyaan sebanyak 6 dan semua dinyatakan valid karena nilai corrected item-total correlation $>0,3$

Tabel 3 Uji Reliabilitas Keselamatan Kerja (X) Reliability Statistic

\begin{tabular}{ll}
\hline Cronbach's Alpha & N of Items \\
\hline .837 & 6 \\
\hline Sumber: Hasil Olahan SPSS 21, (2017)
\end{tabular}

Berdasarkan hasil output reliability variabel Keselamatan Kerja (X) dapat diketahui bahwa variabel tersebut reliabel dengan crombach alpha adalah 0,837 yang berarti 0,837 $>0,70$. Dengan demikian, keseluruhan instrumen pertanyaan kuisioner dalam penelitian ini sudah memiliki reliabilitas yang tinggi.

Tabel 4 Uji Reliabilitas Kinerja Karyawan (Y), Reliability Statistic

\begin{tabular}{cc}
\hline Cronbach's Alpha & N of Items \\
\hline .848 & 6 \\
\hline \multicolumn{2}{c}{ Sumber: Hasil Olahan SPSS 21, (2017) }
\end{tabular}

Sedangkan hasil output reliability variabel Kinerja Karyawan (Y) dapat diketahui bahwa variabel tersebut reliabel dengan crombach alpha adalah 0,848 yang berarti 0,848 $>0,70$. Dengan demikian, keseluruhan instrumen pertanyaan kuisioner dalam penelitian ini sudah memiliki reliabilitas yang tinggi. 


\section{Uji Asumsi Klasik}

Uji normalitas adalah untuk mengetahui apakah distribusi data mengikuti atau mendekati distribusi normal. Uji normalitas dilakukan dengan menggunakan pendekatan Kolmogorov Smirnov.

Dengan menggunakan tingkat signifikansi 5\% maka jika nilai Asymp.sig. (2-tailed) diatas, nilai signifikan 5\% artinya variabel residual berdistribusi normal. Salah satu cara untuk melihat normalitas adalah dengan melihat grafik histrogram dan grafik normal plot yang membandingkan antara dua absorvasi dengan distribusi yang mendekati distribusi normal.

\section{Pendekatan Histogram}

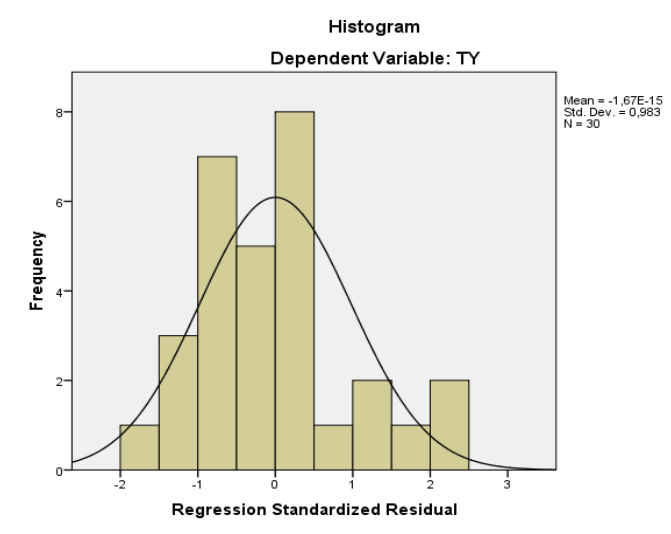

Gambar 1 Histogram Uji Normalitas

Sumber : Hasil pengolahan SPSS 21, (2017)

Berdasarkan Gambar 1 dapat diketahui bahwa variabel berdistribusi normal, hal ini ditunjukkan oleh distribusi data yang berbentuk lonceng dan tidak melenceng ke kiri atau ke kanan.

\section{Pendekatan Grafik}

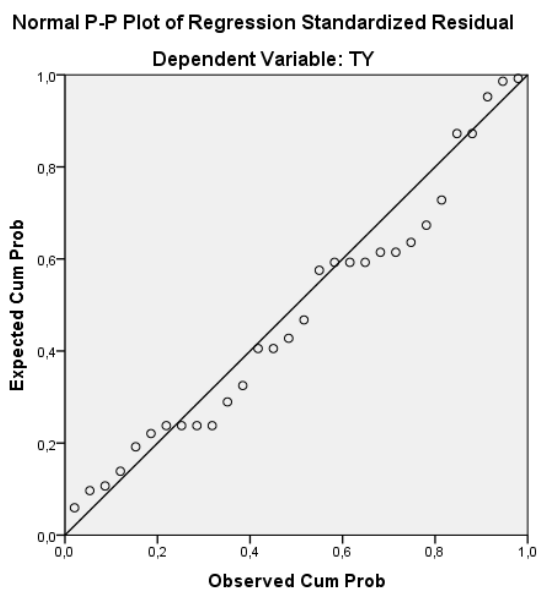

Gambar 2 : Plot Uji Normalitas

Sumber : Hasil Pengolahan SPSS 21 (2017) 
Lukman Nasution \& Reza Nurul Ichsan \&, Pengaruh Keselamatan Kerja Terhadap Kinerja Karyawan Pada

Pengujian normalitas data dapat dilihat dari penyebaran data (titik) pada sumber diagonal grafik normal P-plot akan membentuk satu garis lurus diagonal kemudian plotting data akan dibandingkan antara data yang didistribusikan yang mendekati distribusi normal. Jika distribusi normal maka garis yang menggambarkan data sesungguhnya akan mengikuti garis diagonalnya.

Pada Gambar 2 menunjukkan bahwa pada scatter plot terlihat titik yang mengikuti data di sepanjang garis diagonal. Hal ini menunjukkan bahwa residual peneliti normal.

Tabel 5

Analisis Regresi Sederhana Coefficients ${ }^{\mathrm{a}}$

\begin{tabular}{|c|c|c|c|}
\hline \multirow{2}{*}{\multicolumn{2}{|c|}{ Model }} & \multicolumn{2}{|c|}{ Unstandardized Coefficients } \\
\hline & & $\mathrm{B}$ & Std. Error \\
\hline \multirow{2}{*}{1} & (Constant) & 6,541 & 2,723 \\
\hline & TX &, 771 & ,105 \\
\hline
\end{tabular}

Sumber : Hasil Olahan SPSS 21,2017

Dari tabel 5, dengan memperhatikan angka yang berada pada kolom standardized coefficient beta, maka dapat disusun dengan persamaan regresi sederhana yaitu sebagai berikut:

$$
\mathrm{Y}=6,541+0,771 \mathrm{X}+\sum
$$

Dari persamaan regresi di atas maka dapat diinterpretasikan beberapa hal, antara lain:

1. Nilai Constant (a) $=6,541=$ konstanta

2. Nilai konstanta persamaan diatas adalah sebesar 6,541 menjelaskan bahwa tanpa adanya $\mathrm{X}$ (keselamatan kerja) maka perolehan Y (kinerja karyawan) sebesar 0,771.

3. Nilai $b=0,771$ maka nilai koefisient regresi sebesar 0,771 . Nilai koefisien menunjukkan bahwa X (keselamatan kerja) berpengaruh positif terhadap kinerja karyawan. Hal ini menggambarkan jika terjadi kenaikan keselamatan kerja sebesar satu, maka nilai profitabilitas akan mengalami kenaikan sebesar 0,771 dengan asumsi variabel independen yang lain dianggap konstan.

Bila mana kondisi saat ini sama dengan masa yang akan datang atau waktu yang berbeda, maka generalisasi diatas dapat digunakan atau berlaku. Dengan demikian bila keadaan Cateris Paribus dimana faktor lain yang tidak diikutkan dianggap tetap. Sehingga faktor tersebut dapat diabaikan, maka hasil temuan diatas dapat ditulis sebagai berikut : $Y=6,541+0,771 X$.Tabel 6 Hasil Uji-t Coefficients ${ }^{a}$

\begin{tabular}{cccccc}
\hline \multirow{2}{*}{ Model } & \multicolumn{2}{c}{ Unstandardized Coefficients } & Standardized Coefficients & T & \multirow{2}{*}{ Sig. } \\
\cline { 2 - 4 } & $\mathrm{B}$ & Std. Error & Beta & & \\
\hline (Constan) & 6,541 & $\mathbf{2 , 7 2 3}$ & & 2,402 &, 023 \\
\hline TX &, 771 &, 105 &, 812 & 7,366 & ,000 \\
\hline
\end{tabular}

a. Dependent Variable: TY

Sumber: Hasil Olahan Dari SPSS 21, (2017)

Berdasarkan Tabel 6 dapat diketahui bahwa:

Variabel Keselamatan Kerja adalah 2,402 dengan tingkat signifikansi 0.000 dan nilai ttabel pada alpha $5 \%$ dan df1 = 30 adalah 7,366 variabel keselamatan kerja berpengaruh secara positif dan signifikan terhadap kinerja karyawan PT. PLN (persero) Unit Induk Pembangunan II Medan. Hal ini terlihat dari nilai signifikansi $0.000<0.05$. nilai thitung $(7,366)>$ ttabel 2,763 artinya jika keselamatan kerja ditingkatkan maka kinerja karyawan akan meningkat.

Tabel 7 .

Hasil Pengujian Determinasi $\mathrm{R}^{2}$ Model Summary ${ }^{\mathrm{b}}$

Model Summaryb

\begin{tabular}{lllll}
\hline Model & $\mathrm{R}$ & $\mathrm{R}$ Square & Adjusted R Square & Std. Error of the Estimate \\
\hline 1 &, $812 \mathrm{a}$ & 660 &, 647 & 1,452 \\
\hline
\end{tabular}

a. Predictors: (Constant), TX

b. Dependent Variable: TY

Sumber: Hasil Olahan SPSS V. 21, (2017) 
Dari tabel 7 dapat diketahuai bahwa nilai koefisien korelasi $\left(\mathrm{R}^{2}\right)$ adalah 0,812 atau mendekati 1 yang artinya bahwa tingkat hubungan yang kuat antara komunukasi karyawan dengan kinerja karyawan.

Tabel $\mathrm{R}^{2}$ menunjukkan bahwa nilai koefisien determinasi yang sudah disesuaikan $\left(\mathrm{R}^{2}\right)$ adalah 0,660 atau $34,0 \%$ artinya bahwa kinerja karyawan dipengaruhi oleh keselamatan kerja sebesar $66,0 \%$, sedangkan $34,0 \%$ dipengaruhi oleh variabel lain diluar penelitian ini.

\section{SIMPULAN}

Keselamatan kerja adalah suatu program yang harus diterapkan secara terus menerus terhadap karyawan PT. PLN (Persero) Unit Induk Pembangunan II Medan sesuai dengan undangundang yang berlaku. Program keselamatan kerja sesuai dengan undang-undang yang berlaku pada PT. PLN (Persero) Unit Induk Pembangunan II Medan dapat meningkatkan kinerja karyawan dengan adanya kartu BPJS Ketenagakerjaan akan menjamin karyawan apabila terjadi kecelakaan ditempat kerja langsung dapat diatasi oleh pihak yang dirujuk oleh perusahaan sehingga terhindar dari kematian.

Pengujian regresi linier sederhana menghasilkan persamaan $\mathbf{Y}=\mathbf{6 , 5 4 1}+\mathbf{0 , 7 7 1 X}$. Dari persamaan regresi diatas maka dapat diinterprestasikan beberapa hal antara lain: nilai konstanta persamaan diatas adalah sebesar 6,541 menjelaskan bahwa tanpa adanya X (Keselamatan Kerja) maka perolehan Y (Kinerja Karyawan) sebesar 0,771. Nilai b $=0,771$ memiliki nilai koefisien regresi sebesar 0,771. Nilai koefisien menunjukkan bahwa $\mathrm{X}$ (keselamatan kerja) berpengaruh positif terhadap kinerja karyawan. Hal ini menunjukkan bahwa jika terjadi kenaikan keselamatan kerja sebasar 1 persen, maka nilai profitabilitas akan mengalami kenaikan sebesar 0,771 dengan asumsi variabel independen yang dianggap konstan. Uji t (Parsial) Variabel Keselamatan Kerja adalah 2,402 dengan tingkat signifikansi 0.000 dan nilai ttabel pada alpha $5 \%$ dan df1 $=30$ adalah 7,366 variabel keselamatan kerja berpengaruh secara positif dan signifikan terhadap kinerja karyawan PT. PLN (persero) Unit Induk Pembangunan II Medan. Hal ini terlihat dari nilai signifikansi $0.000<0.05$. nilai thitung $(7,366)$ $>$ ttabel 2,763 artinya jika keselamatan kerja ditingkatkan maka kinerja karyawan akan meningkat.

Koefisien korelasi $\left(\mathrm{R}^{2}\right)$ adalah $0,812^{\text {a }}$ atau mendekati1 yang artinya bahwa tingkat hubungan yang kuat antara keselamatan kerja dengan kinerja karyawan. Sedangkan nilai koefisien determinasi yang sudah disesuaikan ( $\mathrm{R}$ square) adalah 0,660 atau 66,0\% artinya kinerja karyawan dipengaruhi oleh keselamatan kerja sebesar $66,0 \%$, sedangakan $34,0 \%$ dipengaruhi oleh variabel lain.

\section{DAFTAR PUSTAKA}

Bangun, W. (2012). Manajemen Sumber Daya manusia. Bandung: Erlangga.

Haryati, E., Suharyanto, A. Hasmayni, B. \& Siregar, F.H. (2019). The Effect of Work Environment and Work Stress on Employee Performance at PT Aneka Gas Industri Tbk Research Article in Proceedings of the 2nd International Conference on Social Sciences and Interdisciplinary Studies (formerly ICCSSIS), ICCSIS 2019, 24-25 October 2019, Medan, North Sumatera, Indonesia

Kusdyah, I.R. (2008). Manajemen Sumber Daya Manusia, Yogyakarta: ANDI.

Latief, A. Rosalina, D. \& Apiska, D. (2019). Analisis Hubungan Antar Manusia terhadap Kinerja Karyawan. Journal of Education, Humaniora and Social Sciences (JEHSS). 1 (3): 127-131.

Latief, A. Zati, M.R. \& Pribadi, K. (2018). Analisis Faktor Faktor Yang Mempengaruhi Kinerja Karyawan. JUPIIS: Jurnal Pendidikan Ilmu-ilmu Sosial, 10 (2): 167-172.

Latief, A., Nurlina, N., Medagri, E., \& Suharyanto, A. (2019). Pengaruh Manajemen Pengetahuan, Keterampilan dan Sikap terhadap Kinerja Karyawan. JUPIIS: Jurnal Pendidikan Ilmu-Ilmu Sosial, 11(2), 173-182. doi:https://doi.org/10.24114/jupiis.v11i2.12608

Mangkunegara, A.P. (2010), Manajemen Sumber Daya Manusia perusahaan. Bandung: Remaja Rosdakarya. 
Lukman Nasution \& Reza Nurul Ichsan \&, Pengaruh Keselamatan Kerja Terhadap Kinerja Karyawan Pada

Mora, Z., Suharyanto, A., Yahya, M., (2020). Effect of Work Safety and Work Healthy Towards Employee's Productivity in PT. Sisirau Aceh Tamiang, Budapest International Research and Critics Institute, 3(2): 753-760.

Nurlaila. (2010). Manajemen Sumber Daya Manusia I. Ternate: Penerbit LepKhair.

Purnama. (2010). Pengaruh Kondisi Lingkungan Kerja terhadap kelelahan kerjadi Pabri Kertas Rokok PT PDM Indonesia. Program Studi S2 Ilmu Kesehatan Masyarakat FKM USU.

Rivai, V dan Sagala, E.J. (2011). Manajemen Sumber Daya Manusia untuk Perusahaan dari Teori ke Praktik. Jakarta: PT Raja Grafindo.

Sugiyono. (2010). Statistika Untuk Penelitian, Bandung: CV. Alfabeta.

Suma'mur, P.K. (2009). Higiene Perusahaan dan Kesehatan Kerja (HIPERKES). Jakarta: Sagung Seto.

Sunyoto, D. (2012). Manajemen Sumber Daya Manusia. Yogyakarta: CAPS

Sutrisno, E. (2010). Manajemen Sumber Daya Manusia. Jakarta: Prenada Media Group.

Syardiansah, Latief, A., Daud, M.N., Windi, \& Suharyanto, A, (2020), The Effect of Job Satisfaction and Organizational Culture on Employee Performance of the Royal Hotel in East Aceh District, Budapest International Research and Critics Institute, 3(2): 849-857.

Widodo, SE. (2015). Manajemen Pengembangan Sumber Daya Manusia. Yogyakarta: Pustaka Pelajar. 